Professor C. C. de Silva Oration-2015

\title{
Spirometry in children: Meeting the unmet need
}

\section{Guwani Liyanage ${ }^{1}$}

Sri Lanka Journal of Child Health, 2016; 45(3): 151-162

DOI: http://dx.doi.org/10.4038/sljch.v45i3.8151

(Key words: Spirometry, lung function, Sri Lanka)

Professor Cholmondely Chalmers de Silva, born on 25th February 1904, had his early education at St. Thomas' College in Mount Lavinia and entered the Ceylon Medical College in 1922. After a few years in the Ceylon Medical College, he changed his seat of learning to University College and Kings College Hospital in London and graduated in 1928 with MBBS. He obtained his MRCP (London) the same year as he qualified with his MBBS. Later, he obtained MD (London). In 1949 he joined the Faculty of Medicine, University of Ceylon as the first Professor of Paediatrics. He took over a ward in Lady Ridgeway Hospital with "one clinical thermometer and one nurse at night". Unfamiliar conditions for many of us today, yet that was the reality at that time.

His contributions to the profession are numerous. Professor CC's main clinical interests were nutritional disorders, haemoglobinopathies and infective diarrhoeas. The first case of thalassaemia was reported by him. Together with Dr. L.O. Abeyratne, he was instrumental in setting up the convalescent home at Thalagolla for nutritional rehabilitation of malnourished children. He is the founder President of the Nutrition Society of Sri Lanka. Prof CC is fondly remembered by many, for his application of king coconut water intravenously when there had been a shortage of saline. He introduced green plantain (Aanamalu) to malnourished children with diarrhoea that provided calories and shortened the duration of symptoms.

${ }^{1}$ Senior Lecturer / Consultant Paediatrician, Department of Paediatrics, Faculty of Medical Sciences, University of Sri Jayewardenepura

*Correspondence: guwanil@yahoo.co.uk

The author declares that there are no conflicts of interest

Funded by Glaxo-SmithKline Pharmaceuticals and Citi-Health Pharmaceuticals and equipment grant from National Science Foundation, Sri Lanka.

Open Access Article published under the Creative Commons Attribution CC-BY (c) (i)
The pioneering work done by Professor $\mathrm{CC}$ and his leadership, during an era almost seven decades ago, has contributed to the very low infant and childhood mortality rates that we experience today. His research work in Paediatrics is unparalleled to date, considering the efforts that were needed, at a time when the facilities and technology were relatively basic. Prof. CC's contribution to Paediatrics in the academic field are too numerous to mention at length. No doubt, all of us who belong to the community of Paediatricians had been beneficiaries of Prof. CC's scholarly work and teachings from his clinical practice.

It can truly be said that it was Prof. C.C. who put Sri Lanka on the world map of Paediatrics. He passed away peacefully at the age of 83 on 20th May 1987, a few weeks before his autobiography "Life as I lived it" was released. Prof. CC's contribution to Paediatrics has been immense and he will be remembered with honour and gratitude for many years to come. I would now like to dedicate my work in this oration, to a superlative paediatrician of the calibre of Professor Cholmondely Chalmers de Silva, a shining beacon for the paediatricians of our country. I thank the President and the Council of the Sri Lanka College of Paediatricians for giving me this opportunity.

\section{Preamble}

"The lives of too many people in the world are being blighted and cut short by chronic diseases such as heart disease, stroke, cancer, chronic respiratory diseases and diabetes" said Dr. Lee Jong-Wook, the late Director-General of World Health Organisation $(\mathrm{WHO})^{1}$. WHO global status report on noncommunicable diseases (NCDs) 2014 states that NCDs are the leading causes of death, worldwide ${ }^{2}$. It disproportionately affects low- and middle-income countries where nearly three quarters of NCD deaths occur. Human, social and economic consequences of NCDs are felt by all countries. Therefore, reducing the burden of NCDs is an overriding priority. 
If we glance at the WHO country profile for NCDs in 2014 for Sri Lanka, it clearly shows the burden of NCDs on us $^{3}$. Over $75 \%$ of total deaths below 70 years in our country are due to NCDs and $8 \%$ of them are due to chronic respiratory disorders. In the WHO report on global surveillance, prevention and control of chronic respiratory diseases, the burden of asthma is high and only second to allergic rhinitis. The world map on current wheezing, based the International Study of Asthma and Allergies in Childhood (ISAAC) study has placed Sri Lanka in the high prevalence category ${ }^{4}$. Further, a notable number is suffering from chronic obstructive pulmonary disease (COPD). However, incidence of other chronic lung diseases is grossly under reported worldwide and the true incidence is not known.

Daniel Defoe, who authored the world famous novel, Robinson Crusoe, proclaimed "As covetousness is the root of all evil, so poverty is the worst of all snares". Ladies and Gentlemen, chronic diseases and poverty are interconnected in a vicious cycle. Exposures to risks are high among the poor. They have low access to health services. Further, rapid unplanned urbanization, pollution and unhealthy lifestyles contribute heavily to the increased incidence of chronic diseases. Moreover, WHO report on "Comprehensive approach to prevention of chronic respiratory disorders" emphasizes that many other barriers in health care provision exist in developing countries ${ }^{5}$. Hence, the poorest people are most likely to die prematurely from these diseases due to poor access or unavailability of optimal care.

Therefore, at this juncture, I would like to draw your attention to one important barrier that hinders optimal management of chronic respiratory diseases, namely, poor availability of health care facilities that is required for accurate diagnosis, assessment and follow-up of these children. Ladies and Gentlemen, the theme of my oration today revolves around this vital approach of improving the diagnostic and assessment methods of respiratory diseases, advocated by the WHO.

\section{What is spirometry?}

Spirometry is the most commonly performed pulmonary function test measuring volume and flow of air that is inhaled and exhaled. Spirometer, derived from the Latin words SPIRO (to breathe) and METER (to measure) is a valuable clinical tool that measures lung function when investigating and monitoring lung disorders. The earliest attempt to measure lung volumes can be dated back to the time of the Roman Empire. Claudius Galen, who was a Roman doctor and philosopher, had a boy breathe in and out of an animal bladder and found out that the volume of air did not change ${ }^{6}$.

While there were many others who performed similar experiments, nothing significant was recorded until Giovanni Alfonso, an Italian mathematician and a physiologist attempted to measure lung volumes. He is believed to be the first person to make sure that the patient plugs his nose during spirometry testing, which is the practice even today. The real turning point was in 1846 when an effective spirometer was created by John Hutchinson, an English surgeon. He measured the volume of air exhaled from fully inflated lungs and coined the term, "vital capacity", in other words, capacity for life. He believed that there was a strong correlation between vital capacity and death and that it could be utilized for predictions for life insurance policies. However, neither the spirometer nor its measurements were accepted by the insurance industry. During the next 20 years, other names joined the growing list of scientists refining and redesigning the spirometer.

Albert Einstein, once said, "I have no special talents, I am only passionately curious". Curiosity, in a wide sense, is often the principal reason for scientific advances in medicine. As a result, current devices have evolved into more sophisticated easy to use portable hand held and office spirometers. However, Ladies and Gentlemen, once the test is performed interpretation is always a challenge. Measurements obtained have to be compared with reference values formulated for that particular population for accurate interpretation since lung functions are closely related to height, bodyweight, age, sex, race/ethnicity and altitude.

There are many different reference equations available internationally. Third National Health and Nutrition Examination Survey (NHANES III) makes a clear separation between Caucasian, AfricanAmerican and Mexican-American populations ${ }^{7}$. In Europe, the European Community for Steel and Coal (ECSC) reference equations are used ${ }^{8}$. Normative standards for lung function from the United Kingdom (Rosenthal et al) selected non-hospital based children to calculate regression equations ${ }^{9}$. Many other countries all over the world have produced their own reference equations, e.g. South India ${ }^{10}$. The recent Global Lung Function Initiative study (GLI) 2012 of the European Respiratory Society Task Force, established a global spirometric prediction equations for 3 to 95 year-olds ${ }^{11}$. They collected data from 33 countries around the world after a tedious selection process to derive reference values for Caucasians, African-Americans, South East Asians and North 
East Asians: However, data from Sri Lanka, Pakistan and India were not included in this analysis. They concluded that the derived equations can be applied globally to different ethnic groups and additional data from the Indian subcontinent will improve these equations further.

In our country there are some spirometric normative standards for groups of adults. Spirometric and flow standards for healthy non-smoking Sri Lankan young adults belonging to Sinhalese ethnic group and lung function parameters of healthy Sri Lankan Tamil young adults are some of those $\mathrm{e}^{12,13,14}$.

Since we do not have reference values for Sri Lankan children we have been referring to predictions from other Asian countries and European values with a correction factor for Asians. Their suitability for our children has never been investigated. Therefore, Ladies and Gentlemen, I proceeded to design this study, with 2 primary objectives, namely to establish spirometric reference values for healthy Sri Lankan children aged 8-16 years and to compare our Sri Lankan measurements with predictions for Caucasians from United States (NHANES III), South East Asians from GLI 2012 and South Indians.

\section{How did we achieve it?}

The target population was "healthy" children between the ages of 8 and 16 years. Sample calculation was carried out based on variance of PEFR $^{15}$. Non response rate was taken as $5 \%$. Ethical clearance was obtained from Ethics Committee, Faculty of Medical Sciences, University of Sri Jayewardenepura.

Selection was carried out with stratified multistage cluster sampling. In the first stage, we clustered all the districts into five groups considering the population size in each district to assure that highly populated districts are well represented. One district was drawn from each group. In this process, many variables were considered including degree of urbanization, geographic proximity, ethnicity, and altitude. We included Colombo, Jaffna, Monaragala, Nuwara-Eliya and Kalutara districts. There are 2-4 educational zones in each district. One educational zone was selected randomly from each district. The reason to draw only one zone was to minimize the amount of travel necessary in moving from one stand to the next. Thereafter all fee-levying and non-feelevying schools with secondary education were listed, and categorized into girls, boys, and mixed schools. A sub-sample of schools was selected from each educational zone and subsequently three to four classes were randomly picked up from each grade. For Colombo District, we further stratified the schools according to ethnicity to assure a fair representation in the sample by the 3 main ethnic groups. The sampling rate in each school was designed to include the desired number of sample persons for each age-sex domain.

A total of 4211 children was invited for the study. Pre piloted, self-administered, questionnaire, based on the ISAAC study was utilized for data collection ${ }^{4}$. Physical examination was performed and anthropometry (height and weight) was recorded. With the above information, a healthy sample of children was recruited and spirometry was performed. Volume calibration was performed daily by using a 3 litre standard syringe. All efforts were taken to fulfil the American Thoracic Society (2005) recommendations for spirometry ${ }^{16}$. A minimum of 3 and a maximum of 8 manoeuvres were performed to obtain at least two acceptable trials. Finally, 2450 children underwent spirometry and of them 784 girls and 964 boys were considered for inclusion. The reasons for exclusion are tabulated in Table 1. Baseline characteristics of the sample are shown in Table 2.

Table 1: Reasons for exclusion

\begin{tabular}{|l|c|}
\hline \multicolumn{1}{|c|}{ Reason for exclusion } & Number \\
\hline Spirometry not satisfying American Thoracic Society standards & 702 \\
\hline Diagnosis of asthma & 246 \\
\hline Frequent nocturnal cough during preceding 12 months & 72 \\
\hline Frequent whistling and/or wheezing in chest, apart from colds & 203 \\
\hline Exercise induced cough or breathlessness & 42 \\
\hline Long term inhaler or oral medications during the previous year & 201 \\
\hline Other chronic illnesses/recent surgery & 21 \\
\hline Recent respiratory illness or febrile illness during the previous 2 weeks & 116 \\
\hline Not present on the day of spirometry & 452 \\
\hline Incomplete questionnaires/non respondents to questionnaire & 400 \\
\hline Other ethnic groups (Burgher/Malay) & 8 \\
\hline
\end{tabular}


Table 2: Baseline characteristics of the study sample

\begin{tabular}{|c|c|c|c|}
\hline & Male & Female \\
\hline \multicolumn{2}{|l|}{ Subjects (Number) } & 964 & 784 \\
\hline \multicolumn{2}{|c|}{ Height in cm: Mean \pm SD (Range) } & $147.30 \pm 14.20(115-186)$ & $146.20 \pm 11.77(102-178)$ \\
\hline \multicolumn{2}{|c|}{ Weight in kg: Mean \pm SD (Range) } & $36.90 \pm 12.64(17-96)$ & $37.26 \pm 11.49(20-86)$ \\
\hline \multicolumn{2}{|c|}{ Body mass index: Mean \pm SD (Range) } & $16.65 \pm 3.61(10.25-46.65)$ & $17.10 \pm 3.65(10.37-38.95)$ \\
\hline \multirow{9}{*}{$\begin{array}{l}\text { Subjects in each age } \\
\text { group: Number (\%) }\end{array}$} & 8 years & $75(7.4)$ & $64(7.8)$ \\
\hline & 9 years & $95(9.4)$ & $63(7.7)$ \\
\hline & 10 years & $120(11.8)$ & $64(7.8)$ \\
\hline & 11 years & $136(13.4)$ & $102(12.5)$ \\
\hline & 12 years & $143(14.1)$ & $168(20.5)$ \\
\hline & 13 years & $171(16.9)$ & $155(18.9)$ \\
\hline & 14 years & $117(11.5)$ & $104(12.7)$ \\
\hline & 15 years & $72(7.1)$ & $43(5.3)$ \\
\hline & 16 years & $35(3.5)$ & $21(2.6)$ \\
\hline
\end{tabular}

The ethnic distribution is shown in Table 3 and the geographic distribution in Table 4. The mean forced vital capacity (FVC) versus mean standing height for male and female children of different ethnic groups are shown in Figure 1 whilst the mean FVC versus mean standing height for male and female children of different geographic areas are shown in Figure 2.

Table 3: Ethnic distribution

\begin{tabular}{|l|c|c|c|c|}
\hline \multirow{2}{*}{ Sex } & \multicolumn{3}{|c|}{ Ethnicity } & \multirow{2}{*}{ Total } \\
\cline { 2 - 4 } & Sinhalese & Muslim & Tamil & $964(100)$ \\
\hline Males: Number (\%) & $596(61.8)$ & $100(10.4)$ & $268(27.8)$ & $784(100)$ \\
\hline Females: Number (\%) & $545(69.5)$ & $63(8.0)$ & $176(22.4)$ & \\
\hline
\end{tabular}

Table 4: Geographic distribution

\begin{tabular}{|l|c|c|}
\hline \multicolumn{1}{|c|}{ Location } & Male: Number (\%) & Female: Number (\%) \\
\hline Monaragala & $110(11.4)$ & $130(16.6)$ \\
\hline Jaffna & $90(9.3)$ & $82(10.5)$ \\
\hline Nuwara-Eliya & $153(15.9)$ & $100(12.8)$ \\
\hline Kalutara & $165(17.1)$ & $135(17.2)$ \\
\hline Colombo & $446(46.3)$ & $337(43.0)$ \\
\hline
\end{tabular}

(a)

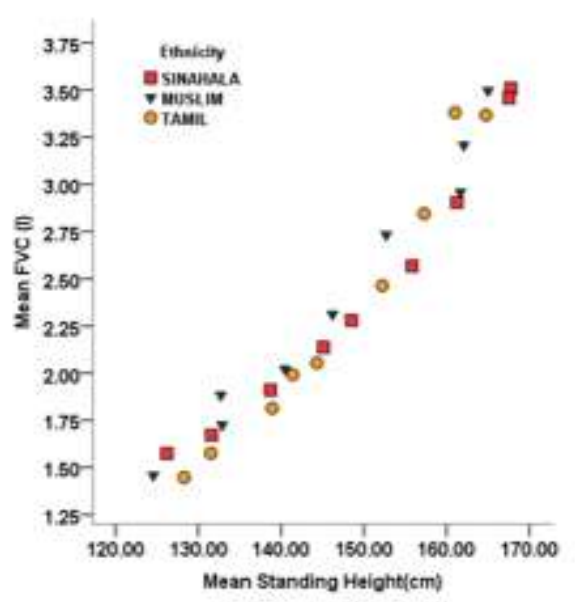

(b)

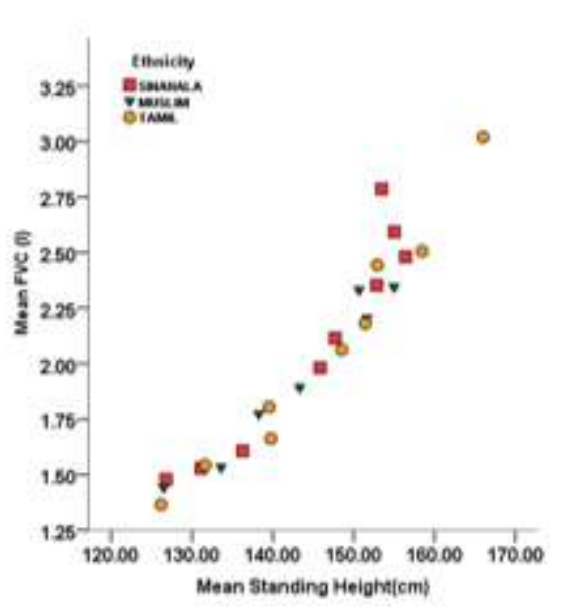

Figure 1: Mean forced vital capacity (FVC) versus mean standing height for male (a) and female (b) children of different ethnic groups 
(a)

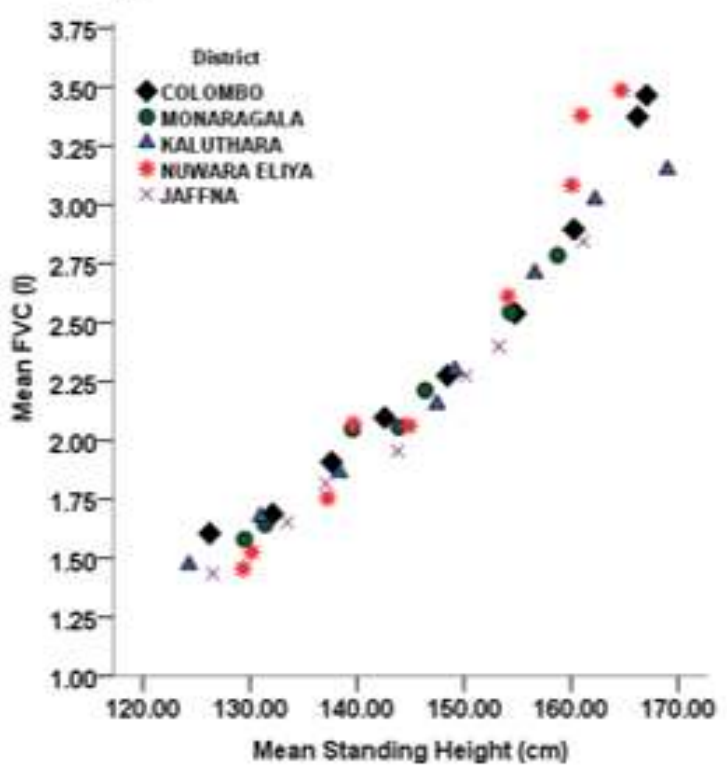

(b)

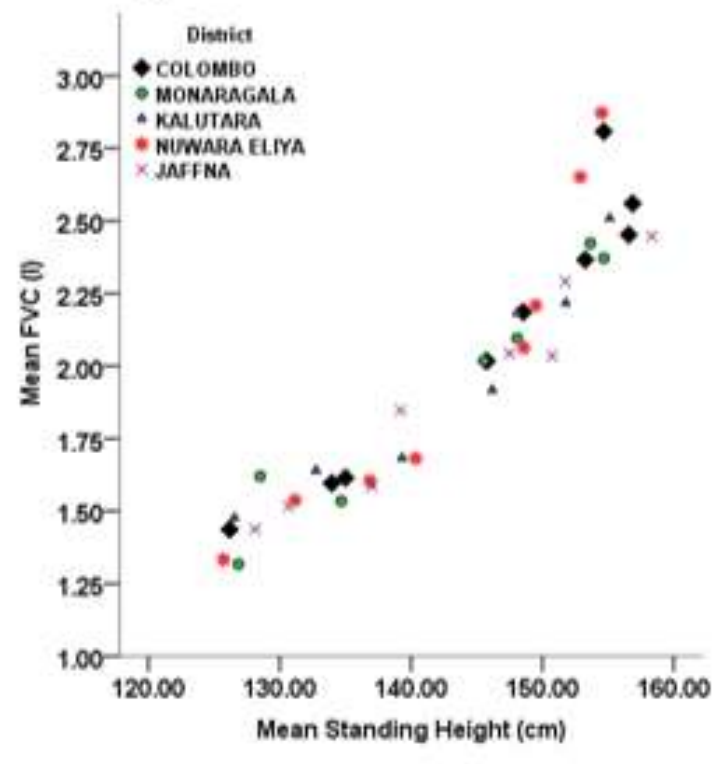

Figure 2: Mean forced vital capacity (FVC) versus mean standing height for male (a) and female (b) children from different geographic areas

Establishing reference values for spirometry for Sri Lankan children

Males on average are taller and heavier than females. Therefore, invariably, different sets of equations are indicated for each gender. We evaluated whether a difference in spirometry parameters and anthropometry are seen among children from different geographic regions and different ethnic groups with multivariate analysis of variance (MANOVA). We concluded that there are no major statistically significant differences, except for very few minor variations. Graphical presentations of these comparisons are shown in Figures 1 and 2 . Therefore, we considered that the sample is homogeneous by geographic region and ethnic group.

Let us now delve into history to support the similarities between different ethnic groups in our country. As we all know, Sinhalese are the descendants of the exiled Prince Vijaya who arrived from Eastern India to Sri Lanka in 543 BC. There had been people identifying themselves as Damelas, the Indo-Aryan word for Tamil people. They had lived in Anuradhapura and other areas of Sri Lanka in the 2nd century BC. A burial jar had been found in Pomparippu, North Western Province of Sri Lanka which is similar to Megalithic Burial Jars found in South India, from the same period. This is evidence that Sri Lankan Tamils had originated from South India. With the arrival of Arab traders in the 7th century AD, Islam began to spread in Sri Lanka. By the 8th century AD, Arab traders had controlled much of the trade in the Indian Ocean, including that of Sri Lanka. They got married to native local women here, after having converted them to Islam. They did not bring women with them and they settled down in large numbers in the country. Later, Javanese, Malaysian and Indian descendants, contributed to growth of the Muslim population. All these considerations seem to indicate that quite a significant lot of us are genetically interrelated.

Considering the sample population as being homogeneous, we proceeded to derive the reference equations for Sri Lankan children. Independent variables considered for inclusion in the models were age, standing height, weight and body mass index (BMI). BMI is a derivative of weight and height and therefore it was left out. There was positive correlation between spirometry parameters and height and age (Figures 3-6) and weight (not shown). Since age is generally a required variable for interpretation of pulmonary function tests, it was retained as a predictor. Based on a general form of equation, we performed multiple regression analysis to identify more independent variables that may improve the 
equation further. Both height and weight were found to be similar in improving the equations; height was taken as the preferred choice. Therefore, weight was left out. Finally Ladies and Gentlemen, we obtained the simplest form of model that could give the most accurate predictions of spirometry parameters for Sri Lankan children between 8-16years based on height and age (Table 5). Height coefficient for lower limit of normal (LLN) predictions is also shown.

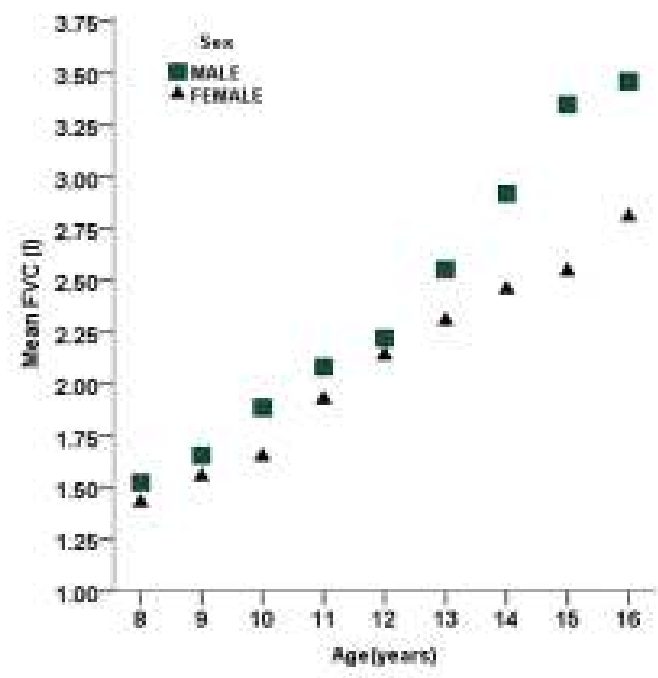

Figure 3: Mean FVC versus age (1-yr increments) for males and females

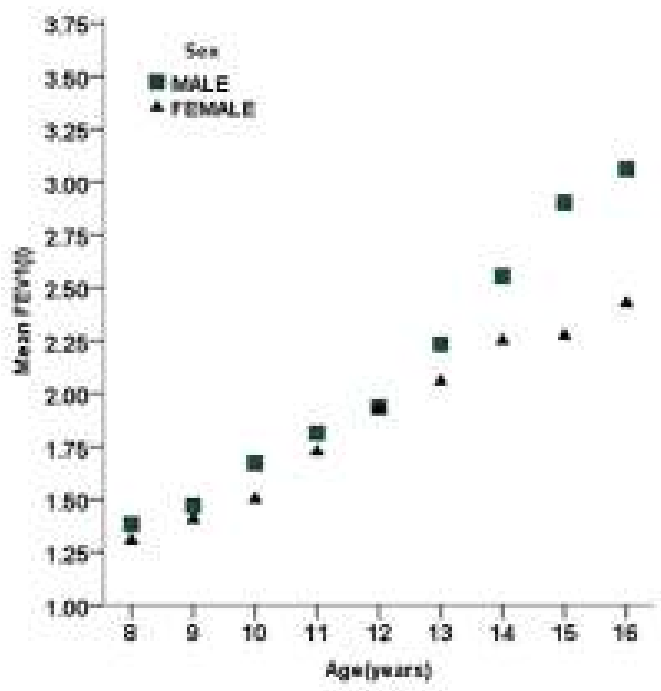

Figure 4: Mean FEVl versus age (1-yr increments) for males and females

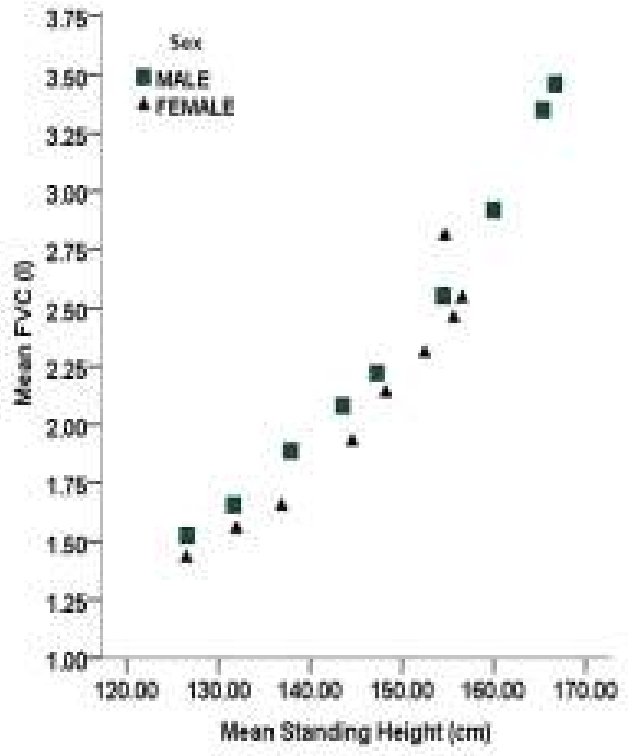

Figure 5: Mean FVC versus standing height for males and females

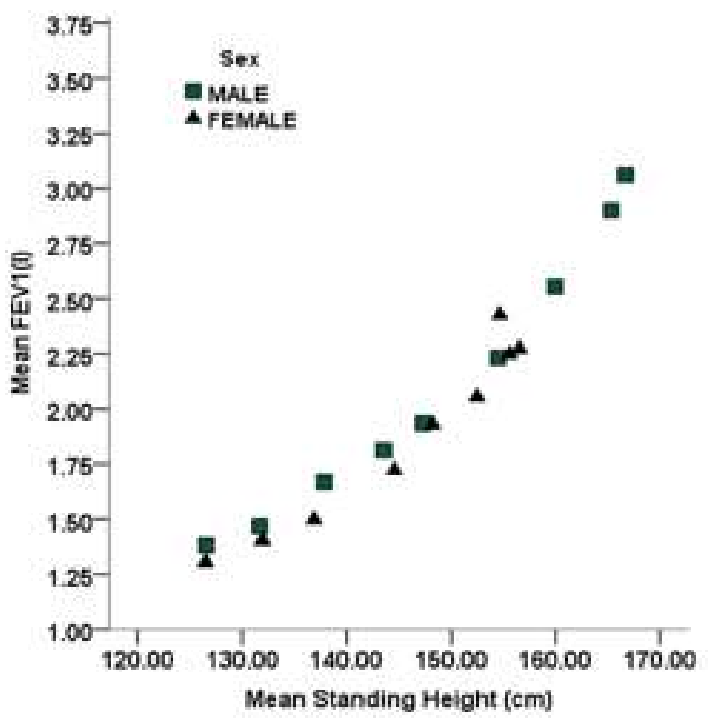

Figure 6: Mean FEV1 versus standing height for males and females 
Table 5: Prediction equations for Sri Lankan children aged 8-16 years using age and height as independent variables

\begin{tabular}{|c|c|c|}
\hline Parameter & Prediction equation & Lower limit of normal (LLN) for height \\
\hline $\begin{array}{ll}\text { Males } & \\
& \text { FVC } \\
& \text { FEV1 } \\
& \text { FEF } 25-75 \% \\
& \text { PEFR }\end{array}$ & $\begin{array}{l}-3.889+0.066 \mathrm{~A}+0.037 \mathrm{H} \\
-3.210+0.067 \mathrm{~A}+0.028 \mathrm{H} \\
-2.619+0.099 \mathrm{~A}+0.027 \mathrm{H} \\
-5.515+0.252 \mathrm{~A}+0.047 \mathrm{H}\end{array}$ & $\begin{array}{l}0.035 \mathrm{H} \\
0.028 \mathrm{H} \\
0.023 \mathrm{H} \\
0.040 \mathrm{H}\end{array}$ \\
\hline $\begin{array}{l}\text { Females } \\
\text { FVC } \\
\text { FEV1 } \\
\text { FEF 25-75\% } \\
\text { PEFR }\end{array}$ & $\begin{array}{l}-2.625+0.071 \mathrm{~A}+0.026 \mathrm{H} \\
-2.227+0.062 \mathrm{~A}+0.023 \mathrm{H} \\
-2.205+0.096 \mathrm{~A}+0.024 \mathrm{H} \\
-2.968+0.203 \mathrm{~A}+0.023 \mathrm{H}\end{array}$ & $\begin{array}{l}0.024 \mathrm{H} \\
0.021 \mathrm{H} \\
0.020 \mathrm{H} \\
0.023 \mathrm{H}\end{array}$ \\
\hline
\end{tabular}

*Lower limit of normal (5th percentile) is estimated as height coefficient - $1.64 \times$ S.E. of height coefficient).

$H$ : height in metres, $A$ : age in years, S.E.: Standard error

Vince Lombardi was an American football player and a coach. He was considered by many as one of the best and most successful coaches in National Football League history in the USA. He is noted to have said, "Perfection is not attainable, but if we chase perfection we can catch excellence". At this juncture, Ladies and Gentlemen, I would like to explain, how and why we attempted to reach perfection. In our study, respiratory volumes and flows of males showed an upward deviation with puberty. However in females it was a smooth curve which was quite linear. This raised a suspicion in our minds whether equations for males in particular will need further refinement. Thus, piece-wise regression was applied. Yet, there was no improvement in precision of the equations. Therefore, we could not justify any adjustment to the equations for males.

My next task was to compare our reference values with other reference values available internationally. A comparison with other studies of Caucasian subjects - NHANES III, South East Asians - GLI 2012 and South Indian - Vijayan et al are shown in Table 6, Figure 7 (males) and Figure 8 (females).

Table 6: Comparison of predicted LLN (our study) with predicted LLN of NHANES for Caucasians, GLI 2012 for SE Asians and South Indians

\begin{tabular}{|c|c|c|c|c|c|c|c|}
\hline \multirow[b]{2}{*}{ Parameter } & \multirow[b]{2}{*}{ Study } & \multicolumn{3}{|c|}{ Males } & \multicolumn{3}{|c|}{ Females } \\
\hline & & $\begin{array}{l}\frac{\text { Mean of }}{\text { individual }} \\
\underline{\text { subject }} \\
\text { difference \% }\end{array}$ & $\begin{array}{l}\text { Absolute } \\
\text { difference } \\
\end{array}$ & $\begin{array}{l}\underline{Z} \\
\underline{\text { Score }} \\
\end{array}$ & $\begin{array}{l}\text { Mean of } \\
\underline{\text { individual }} \\
\underline{\text { subject }} \\
\text { difference \% }\end{array}$ & $\begin{array}{l}\text { Absolute } \\
\text { difference } \\
\end{array}$ & $\underline{\text { Z Score }}$ \\
\hline \multirow[t]{3}{*}{$\mathrm{FVC}$} & NHANES & -5.685 & -0.130 & -0.130 & -4.835 & -0.100 & -0.197 \\
\hline & GLI (SE Asian) & -16.792 & -0.326 & -0.475 & -21.443 & -0.371 & -0.786 \\
\hline & South Indian & 1.967 & 0.061 & 0.061 & 3.326 & 0.159 & 0.290 \\
\hline \multirow[t]{3}{*}{ FEV1 } & NHANES & -11.222 & -0.198 & -0.198 & -11.449 & -0.170 & -0.404 \\
\hline & GLI (SE Asian) & -19.880 & -0.316 & -0.557 & -14.263 & -0.229 & -0.563 \\
\hline & South Indian & 2.385 & 0.038 & 0.038 & 3.655 & 0.020 & 0.043 \\
\hline \multirow[t]{3}{*}{ FEF 25-75 } & NHANES & 16.705 & 0.326 & 0.326 & 1.794 & 0.046 & 0.352 \\
\hline & GLI (SE Asian) & 4.865 & 0.106 & 0.212 & 7.184 & 7.184 & 0.421 \\
\hline & South Indian & - & - & - & - & - & - \\
\hline \multirow[t]{3}{*}{ PEFR } & NHANES & -9.503 & -0.283 & -0.283 & -13.159 & -0.362 & -0.451 \\
\hline & GLI (SE Asian) & - & - & - & - & - & - \\
\hline & South Indian & - & - & - & - & - & - \\
\hline
\end{tabular}




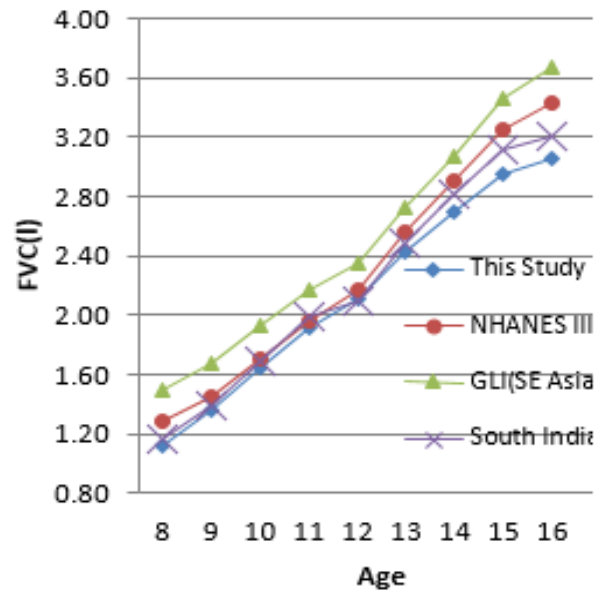

Figure 7: Predicted FVC versus age using equations from current study, NHANES, GLI 2012 and South Indian, in males

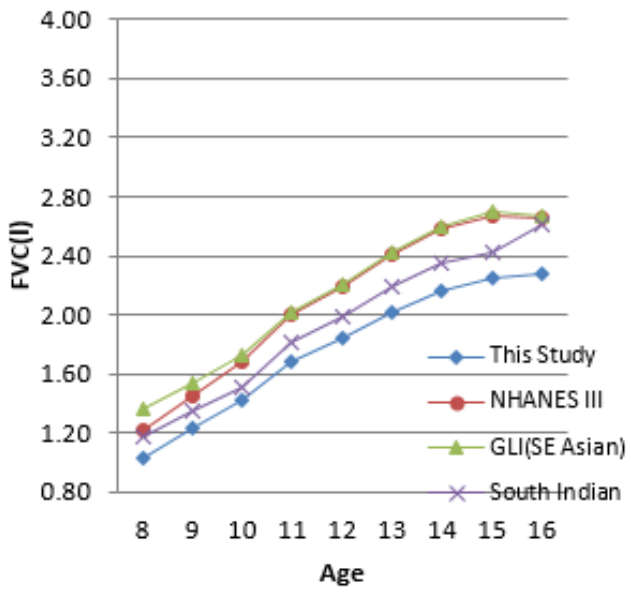

Figure 8: Predicted FVC versus age using equations from current study, NHANES, GLI 2012 and South Indian, in females

Reference values from the present study for FVC are similar to South Indian males and slightly lower in females. Both in females and males GLI 2012 for South East Asians are higher than the FVC values of the present study. A FVC comparison of NHANES III for Caucasian males shows similar or slightly higher values (below 12 years) and up to $400 \mathrm{ml}$ higher FVC (above 12 years) when compared to the present study. On the other hand Caucasian females have higher FVC values throughout the age group. Similar results (not shown) were obtained for FEV1 comparisons with the exception that Caucasian males had higher FEV1 higher values throughout the age group.

In conclusion, there are more pronounced differences in the predicted values for FEV1 and FVC between
GLI 2012 for South East Asians and NHANES III fir Caucasians. The predicted values for FVC and FEV1 tend to be highest for GLI 2012 (South East Asians). However, South Indian values are similar or slightly higher. Therefore, use of South Indian reference equations for predictions of spirometry parameters in Sri Lankan children will only lead to limited changes in the predicted values of FEV1 and FVC for children between 8-16 years. In contrast, users of GLI 2012 or NHANES III prediction equations should be aware that predicted values for FEV1 and FVC will increase substantially.

Chest circumference (CC) as an independent predictor of spirometry parameters in children

Having derived reference values with age and height as variables, I would like to pose another question to you. How would you interpret spirometry parameters in a child who cannot stand up to measure his/her height accurately? As a solution we hypothesized that chest circumference could be utilized as an independent parameter to derive a different set of equations. Thus, we designed this study as another arm of the main study, to evaluate chest circumference as an independent predictor of spirometry reference values.

We only recruited males due to measurement difficulties anticipated with females and measurement errors that could occur as a result of breast size around puberty. Chest circumference of males was measured with a non-stretchable tape by a trained investigator. It was measured in a plane that passes just above the lower angle of scapula behind, just above the nipples in front and high in the armpit at the side. All efforts were taken to take the measurement in expiration.

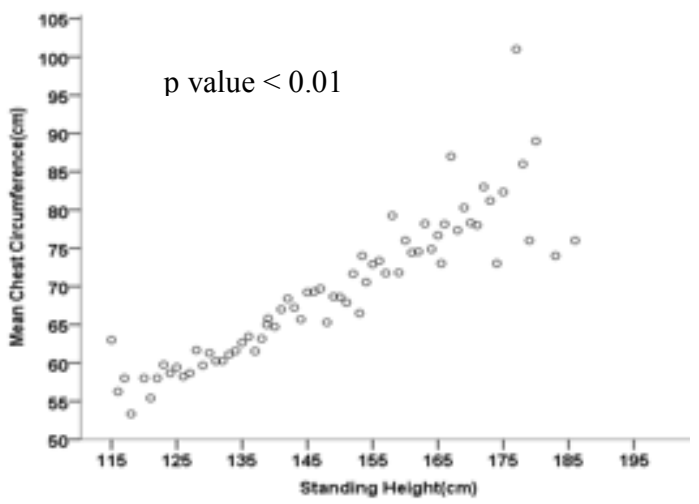

Figure 9: Correlation between height and chest circumference 
Spirograms of six hundred and eighty two children between 8-16 years were included in the analysis. Relationship between height and chest circumference was looked at. Height is positively correlated to chest circumference (figure 9). This confirmed that chest circumference is a potential surrogate marker for

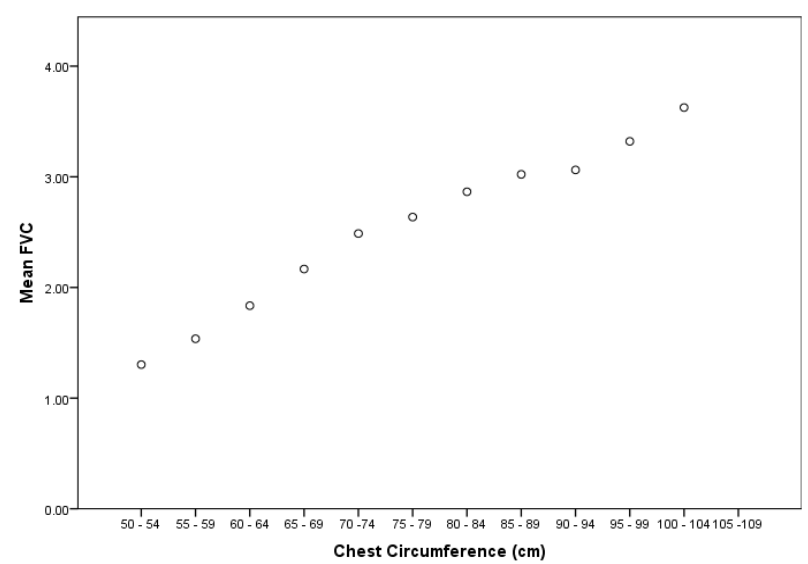

height in situations where measurement of the actual height is challenging.

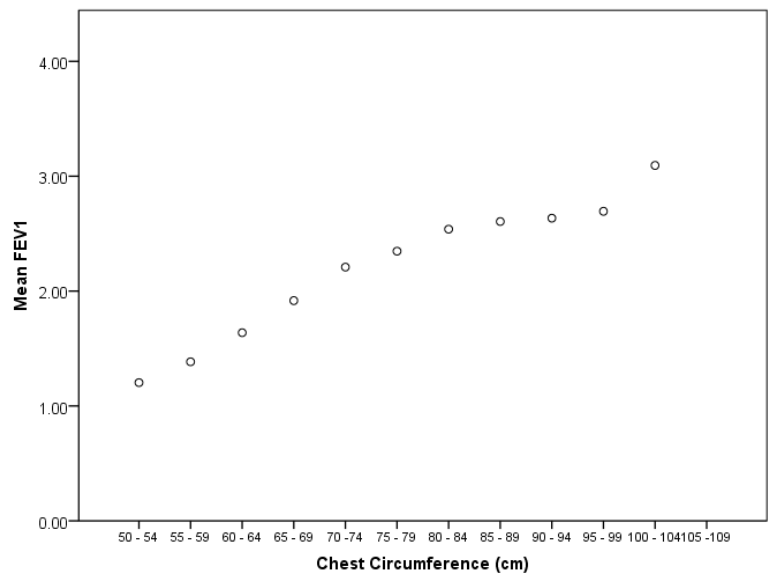

Figure 10: Mean FVC and FEV1 versus chest circumference (cm) for males

Positive correlation was observed between lung volumes and chest circumference (figure 10). Equations to predict spirometry parameters were derived with multiple linear regressions, using age and chest circumference as independent variables (Table 7).

Table 7: Prediction equations for spirometry parameters using chest circumference \& age based on the model: $\alpha$ $+\beta_{1} \times$ age $+\beta_{1} \times$ Chest circumference

\begin{tabular}{|c|c|c|c|c|}
\hline Parameter & Constant ( $\alpha)$ & Age coefficient $\left(\beta_{1}\right)$ & CC coefficient $\left(\beta_{2}\right)$ & $\mathbf{R}^{2}$ \\
\hline FVC & -2.02 & 0.16 & 0.04 & 85.9 \\
\hline FEV1 & -1.57 & 0.14 & 0.28 & 84.4 \\
\hline FEF $25-75 \%$ & -1.04 & 0.17 & 0.22 & 64.7 \\
\hline PEFR & -2.67 & 0.36 & 0.04 & 76.3 \\
\hline
\end{tabular}

We compared the measured value with predicetd values with chest circumference, predicted values the new equations for Sri Lankan children based on height (in a random sub sample) and predictions form height derived from chest circumference. Since there was no significant difference noted, chest circumference could be used as a surrogate for height for interpretation of spirometry parameters in special situations.

Table 8: Group comparisons - observed/measured values vs predicted values based on chest circumference, predicted from new eqations based on height and height derived from chest circumference.

\begin{tabular}{|l|l|l|l|l|l|l|l|}
\hline Parameter & $\begin{array}{c}\text { Observed } \\
\text { values } \pm \\
\text { SD }\end{array}$ & $\begin{array}{c}\text { Predicted by } \\
\text { CC }\end{array}$ & $\begin{array}{c}\mathrm{p} \\
\text { value* }\end{array}$ & $\begin{array}{c}\text { Predicted by new } \\
\text { equations based } \\
\text { on height }\end{array}$ & $\begin{array}{c}\mathrm{p} \\
\text { value* }\end{array}$ & $\begin{array}{c}\text { Predicted by } \\
\text { height derived } \\
\text { from CC }\end{array}$ & $\begin{array}{c}\mathrm{p} \\
\text { value* }\end{array}$ \\
\hline FVC & $2.32 \pm 0.71$ & $2.35 \pm 0.64$ & 0.38 & $2.36 \pm 0.75$ & 0.83 & $2.36 \pm 0.63$ & 0.21 \\
\hline FEV1 & $2.03 \pm 0.61$ & $2.066 \pm 0.54$ & 0.93 & $2.06 \pm 0.64$ & 0.24 & $2.02 \pm 0.54$ & 0.11 \\
\hline FEF 25-75\% & $2.52 \pm 0.83$ & $2.53 \pm 0.56$ & 0.69 & $2.54 \pm 0.87$ & 0.93 & $2.54 \pm 0.58$ & 0.78 \\
\hline PEFR & $4.35 \pm 1.42$ & $4.48 \pm 1.13$ & 0.61 & $4.49 \pm 1.51$ & 0.03 & $4.41 \pm 1.18$ & 0.15 \\
\hline
\end{tabular}

*Level of significance set at $\mathrm{P}<0.01$ to account for multiple comparisons 


\section{Does Obesity/overweight affect the lung volume and flows?}

Obesity is a risk factor for asthma and atopy. We all know that there's a current epidemic of obesity and overweight among both children and adults ${ }^{17}$. In adults, pulmonary function abnormalities are well reported as complications of obesity and overweight ${ }^{18}$. However, in children available data is limited and controversial.

Thus, "healthy" children between 9-15 years were recruited for this cross-sectional survey which was conducted in Colombo metropolitan area. These children with acceptable spirometry values were grouped according to BMI. 'Obese/overweight' group included children with BMI for the age and sex more than the 85th percentile according to CDC (Centre for Diseases Control \& Prevention) reference charts. Overweight was defined as BMI between $85^{\text {th }}$ and $95^{\text {th }}$ percentile and obesity as BMI $>95^{\text {th }}$ percentile. Children between $5^{\text {th }}$ to $85^{\text {th }}$ percentiles were considered 'normal weight'. BMI with $<5^{\text {th }}$ percentile was defined as 'underweight'. Finally results of 55 children with BMI $>85^{\text {th }}$ percentile and a representative sub-group of 64 children between $5^{\text {th }}$ to $85^{\text {th }}$ percentile were analyzed.

Table 9: Comparison of dynamic lung volumes among 'obese/overweight' and 'normal weight' groups

\begin{tabular}{|c|c|c|c|c|c|c|}
\hline \multirow[t]{2}{*}{ Parameter } & \multicolumn{2}{|c|}{$\begin{array}{c}\text { Obese/overweight }\left(\mathrm{BMI}>\mathbf{8 5}^{\text {th }}\right. \\
\text { percentile) }\end{array}$} & \multicolumn{2}{|c|}{$\begin{array}{l}\text { Normal weight (BMI } 5^{\text {th }}- \\
85^{\text {th }} \text { percentile) }\end{array}$} & \multirow{2}{*}{$\begin{array}{c}95 \% \\
\text { confidence } \\
\text { interval }\end{array}$} & \multirow[t]{2}{*}{ p value } \\
\hline & Mean & SD & Mean & SD & & \\
\hline FVC & 2.36 & 0.07 & 2.19 & 0.06 & $(-0.02,0.37)$ & 0.90 \\
\hline FEV1 & 2.05 & 0.06 & 1.93 & 0.05 & $(-0.05,0.28)$ & 0.17 \\
\hline FEV1/FVC & 83.89 & 2.26 & 87.85 & 0.61 & $(-8.32,0.40)$ & 0.07 \\
\hline FEF $25-75 \%$ & 2.49 & 0.09 & 2.37 & 0.06 & $(-0.10-0.34)$ & 0.29 \\
\hline
\end{tabular}

There was no statistically significant difference noted in spirometry parameters irrespective of whether child was normal weight, overweight or obese (Table 9).

These findings are supported by a few other studies. However, some studies have shown conflicting results ${ }^{19,20,21}$. This discrepancy that is observed between studies investigating relationship between spirometry parameters and obesity/overweight could be explained in many ways. Methodological differences such as dissimilar criteria in measuring the fat mass or sample size may have played a role. Further, distribution of body fat in different populations, degree of obesity and duration of obesity in the samples recruited may have an effect on pulmonary function. This variability in results may also be due to positive effect of growth masking the negative effects of obesity on lung function. However, it is recommended to explore this area further with more sophisticated and reliable methods and a bigger sample population.

Ladies and Gentlemen, I am delighted to say that our team has achieved a goal of meeting an unmet need for children with chronic respiratory disorders. We presume that children in our country will benefit from the information that was presented to you today; I believe that this will be useful for diagnostic purposes and will also form a treasure trove for research.
I have reached the exit. It is only the first leg of a long journey. Our prediction equations did not include the early school aged and pre-school children. Therefore, in my journey next task would be to formulate a reference equation for children aged 4-7 years.

\section{How would I achieve that?}

This is a difficult age group. Their exhalation time is short. Carrying out the procedure is difficult since they might not be able to relate to specific instructions. Few adjustments, such as cutting down, blowing time for only one second instead of 3 seconds and deriving FEV 0.75 instead of FEV1, would be more practical.

Next task would be even more difficult, but achievable. We all feel the need for continuous reference equations from childhood to adulthood. Therefore, the aim would be to amalgamate all the existing reference equations from child to adult. That would allow continuity of reference data across the entire age range.

\section{Acknowledgements}

I would like to convey my sincere appreciation to my team of energetic individuals, who helped me every step of the way. They are: Dr. B D Jayamanne, Medical Officer, Health Informatics, National Dengue Control Unit, Dr. M Aqiff, Medical Officer, Professorial Paediatric Unit. Colombo South Teaching Hospital, Dr. Lakkhana Seneviratne, Dr. F 
Q Jayah and Dr. Sujani Sandamali, Department of Paediatrics, Faculty of Medical Sciences, University of Sri Jayewardenepura, Mr. Asitha Weerasuriya, Technical officer, Department of Paediatrics, Faculty of Medical Sciences, University of Sri Jayewardenepura, Dr. H S R Perera, Department of Forensic Medicine, South Asian Institute of Technology and Medicine. Finally I express my gratitude to the principals, teachers and students of all the schools.

Funding: Glaxo-SmithKline Pharmaceuticals, CitiHealth Pharmaceuticals and equipment grant from National Science Foundation, Sri Lanka.

\section{References}

1. Lee J. Global health improvement and WHO: shaping the future. Lancet. 2003; 362(9401): 2083-8.

2. World Health Organization. Global status report on non-communicable diseases 2014. http://www.who.int/nmh/publications/ncdstatus-report-2014/en/

3. World Health Organization. Non communicable disease country profile 2014. http://www.who.int/nmh/publications/ncdprofiles-2014/en/

4. Lai CKW, Beasley R, Crane J, Foliaki S, Shah J, Weiland S. Global variation in the prevalence and severity of asthma symptoms: Phase Three of the International Study of Asthma and Allergies in Childhood (ISAAC). Thorax. 2009; 64:476-83. http://dx.doi.org/10.1136/thx.2008.106609 PMid: 19237391

5. World Health Organization. Global surveillance, prevention and control of chronic respiratory diseases: A comprehensive approach. 2007. http://www.who.int/respiratory/publications/g lobal_surveillance/en/

6. Spirometry. Available from: https://en.wikipedia.org/wiki/Spirometry

7. Hankinson JL, Odencrantz JR, Fedan KB. Spirometric reference values from a sample of the general U.S. population. American Journal of Respiratory and Critical Care Med. 1999; 159:179-87. http://dx.doi.org/10.1164/ajrccm.159.1.9712108 PMid: 9872837

8. Degens P, Merget. Reference values for spirometry of the European Coal and Steel Community: time for change. European Respiratory Journal 2008; 31: 687-8 http://dx.doi.org/10.1183/09031936.0014550 7 PMid: 18310407

9. Rosenthal M, Bain SH, Cramer D, Helms P, Denison D, Bush A, Warner JO. Lung function in white children aged 4 to 19 years: I-Spirometry. Thorax 1993;48:794-802 http://dx.doi.org/10.1136/thx.48.8.803 PMid: 8211868 PMCid: PMC464704

10. Vijayan VK, Reetha AM, Kuppurao KV, Venkatesan P, Thilakavathy S. Pulmonary function in normal South Indian children aged 7 to 19 years. Indian Journal of Chest Diseases and Allied Sciences 2000; 42:14756

PMid: 11089318

11. Quanjer PH, Stanojevic S, Cole TJ, et al. Multi-ethnic reference values for spirometry for the 3-95-yr age range: the global lung function 2012 equations. European Respiratory Journal .2012; 40: 1324-43. http://dx.doi.org/10.1183/09031936.0008031 2

PMid: 22743675 PMCid: PMC3786581

12. Udupihille M. Spirometric and flow standards for healthy adult non-smoking Sri Lankans belonging to the Sinhalese ethnic group. Annals of Human Biology 1995; 22:321-36. http://dx.doi.org/10.1080/0301446950000399 2 PMid: 8849210

13. Udupihille M. Lung function in young Sri Lankan females. Journal of National Science Council of Sri Lanka 1988; 16:229-32.

14. M Balasubramaniam, $\mathrm{K}$ Sivapalan, $\mathrm{R}$ Thuvarathipan. Lung function parameters of healthy Sri Lankan Tamil young adults. Sri Lanka Journal of Child Health. 2014; 59: 4953 http://dx.doi.org/10.4038/cmj.v59i2.7063 
15. Dasgupta A, Ghoshal AG, Mukhopadhyay A, et al. Reference equation for spirometry interpretation for Eastern India. Lung India. 2015; 32:34-9.

http://dx.doi.org/10.4103/0970-2113.148443

PMid: 25624594 PMCid: PMC4298915

16. Miller MR, Hankinson J, Brusasco V, Burgos F, Casaburi R, Coates A et al. Standardisation of spirometry . European Respiratory Journal 2005; 26: 319-38

http://dx.doi.org/10.1183/09031936.05.00034

805

PMid: 16055882

17. WHO. Obesity: preventing and managing the global epidemic: report of a WHO consultation. WHO technical report series; 894. World Health Organization. 1999.

18. Zammit C, Liddicoat H, Moonsie I, Makker H. Obesity and respiratory diseases. International Journal of General Medicine 2010; 3:335-43.

PMid: 21116339 PMCid: PMC2990395
19. Lazarus R, Colditz G, Berkey CS, Speizer FE. Effects of body fat on ventilatory function in children and adolescents: Crosssectional findings from a random population sample of school children. Pediatric Pulmonology 1997; 24:187-94.

http://dx.doi.org/10.1002/(SICI)10990496(19 9709)24:3<187::AID-PPUL4>3.0.CO;2-K

20. Torun E, Cakir E, Ozguç F, Ozgen IT. The Effect of Obesity Degree on Childhood Pulmonary Function Tests. Balkan Medical Journal 2014; 31:235-8.

http://dx.doi.org/10.5152/balkanmedj.2014.1

3101

PMid: 25337419 PMCid: PMC4204752

21. Paralikar SJ, Kathrotia RG, Pathak NR, Jani MB. Assessment of pulmonary functions in obese adolescent boys. Lung India 2012; 29:236-40.

http://dx.doi.org/10.4103/0970-2113.99106

PMid: 22919162 PMCid: PMC3424862 